\title{
ДИДАКТИКА
}

\author{
Н.А. Рыбакова
}

\section{ОСНОВНЫЕ ПРИНЦИПЫ ПОДГОТОВКИ СТУДЕНТОВ НЕЯЗЫКОВОГО ПРОФИЛЯ К ПРОФЕССИОНАЛЬНОЙ МЕЖКУЛЬТУРНОЙ КОММУНИКАЦИИ}

Аннотация. Объектом исследования в статье является обучение студентов нелингвистического профиля иностранному языку и подготовка их к профессиональной межкультурной коммуникации. Предмет исследования - основные принципы данного педагогического процесса с учётом его специфики. Автор рассматривает принципы методики преподавания иностранного языка как частной дидактики и вытекающие из них принципы языковой подготовки нелингвистов. Особое внимание уделяется важности подготовки к межкультурной профессиональной коммуникации в контексте как мировых тенденций, так и явлений, происходящих в нашей стране. Методом исследования в статье является дидактический анализ, а также эмпирические данные, полученные в результате многолетних наблюдений во время работы в нелингвистичесикх вузах.

Основные выводы автора заключаются в том, что для лингвистического обеспечения профессиональной межкультурной коммуникации сегодня не достаточно одних переводчиков. Необходимость владения иностранными языками возрастает для профессионалов всех направлений и профилей, и их языковая подготовка должна носить систематический и планомерный характер, а также быть осмысленной теоретически. Новизна статьи обусловлена тем, что в ней раскрыты и обоснованы принципы подготовки к межкультурной профессиональной коммуникации именно в контексте обучения студентов нелингвистических направлений с учётом педагогической специфики данного прочесса.

Ключевые слова: иностранный язык, межкультурная коммуникация, мотивация, принцип, дидактика, методика, профессиональная коммуникация, высшая школа, глобализация, подготовка.

Review: The object of the research in this article is the training of non-linguist students for professional cross-cultural communication. The subject of the research is the main principles of this process and its specificity. The author analyses linguodidactic principles and those of teaching foreign languages to non-linguists as ensuing them. Particular attention is paid to the importance of training for professional cross-cultural communication in terms of global tendencies and changes taking place in our country. The method of the research in this article is the didactic analysis and empiric data obtained from long observations in the process of working at non-linguistic institutes. The main author's conclusions are the following. For linguistic support of cross-cultural communication translators and interpreters are not enough. Necessity of knowing foreign languages for all professionals increases and their language training must be proved theoretically and have a systematic and planned order. The novelty of the article is caused by the fact that the author reveals and proves principles of training non-linguistic students for professional cross-cultural communication considering pedagogical specificity of this process.

Keywords: professional communication, methodology, theory of education, principle, motivation, cross-cultural communication, foreign language, higher school, globalization, training.

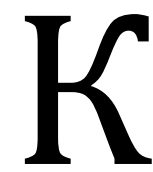
онец XX - начало XXI вв. ознаменовались такими тенденциями и мировыми явлениями как глобализация, взаимная интеграция, мультикультурализм, полиэтничность, толерантность, социальная мобильность, взаимопроникновение культур, информатизация и компьютеризация, в результате чего мы живём в эпоху постепенного исчезновения культурных и этнических границ. В этой связи всё большую актуальность приобретает проблематика межкуль- 
турной и межъязыковой коммуникации. Одной из важнейших задач в этой связи является её лингвистическое обеспечение, поскольку именно в процессе вербальной коммуникации передаётся эксплицитная информация, которая служит основой взаимопонимания представителей даже одной культуры, не говоря уже о людях разных языковых сообществ $[1 ; 2 ; 3]$.

Вместе с тем за последние три десятилетия в нашей стране произошли радикальные социально-экономические и политические изменения, в результате чего мы стали более открытыми для мирового сообщества, увеличилось число международных контактов не только на уровне государства, но и на уровне организаций, компаний и граждан, работающих в них. С другой стороны, представляется, что данный период нашей страны можно охарактеризовать как переходный, и её модернизация, осложняющаяся экономическим кризисом, ещё не завершена. Реформы в области высшего образования, которое несколько лет назад полностью перешло на Болонскую систему, показывают, что мы стремимся к унификации отечественной и европейской образовательных систем, что могло бы поспособствовать академической и профессиональной мобильности, а также межкультурному обмену профессиональным опытом [4; 5; 6].

Однако вопрос качества подготовки специалистов (или теперь бакалавров и магистров) стоит по-прежнему довольно остро, поскольку несмотря на изменение квалификаций, классификаций направлений подготовки, учебных планов и других регулирующих образовательную деятельность документов, реальные знания и профессиональные умения студентов зависят в первую очередь от работы конкретных педагогов и от организации работы в вузе [7; 8; 9]. В условиях изменений в отечественном высшем образовании потребность в специалистах по межкультурной коммуникации не ослабевает, а возрастает. Тем не менее российская высшая школа обладает прекрасными традициями в подготовке профессиональных переводчиков и даже в условиях нестабильности может справиться с этой задачей.

Однако в последнее время всё больше говорится о важности лингвистической подготовки для специалистов неязыкового профиля. Действительно, сотрудник международной фирмы во время командировок за границу не может постоянно находиться с переводчиком. Это сложно технически, а кроме того профессиональная коммуникация в менее формальных ситуациях часто граничит с межличностной, в результате чего третье лицо будет выступать скорее помехой в налаживании контактов представителей разных культур. Кроме того современные тенденции рынка труда показывают, что в условиях кризиса и сокращений, а также экономии бюджетов, специалисты неязыкового профиля со знанием иностранных языков ценятся больше, чем лингвисты, поскольку представляются более универсальными сотрудниками, особенно там, где языком нужно пользоваться практически $[10 ; 11 ; 12 ; 13]$.

Подготовка специалистов неязыкового профиля к профессиональной межкультурной коммуникации, как правило, в вузах организована достаточно слабо. На это есть ряд как объективных, так и субъективных причин. Однако факт то, что дисциплина «Иностранный язык», которая преподаётся на первых двух курсах, как и многие общеобразовательные предметы, зачастую воспринимается как формальность как студентами, так и самими преподавателями, которые не предъявляют должного уровня требований к обучающимся и самим себе, оправдываясь тем, что данная дисциплина непрофильная и глубокое её освоение было бы излишнем [14]. Между тем современные тенденции, описанные выше, ведут к тому, что иностранный язык становится профильным абсолютно для всех вне зависимости от направления подготовки. Для того чтобы организовать лингвистическую подготовку студентов неязыкового профиля, помимо грамотных преподавателей необходимо её теоретическое осмысление. Именно оно сделает данный процесс системным и целенаправленным. Ключевыми в этом смысле представляются принципы обучения нелингвистов иностранному языку. Именно они являются наиболее общими дидактическими законами, которым подчиняется учебный процесс.

Методика обучения иностранному языку является прикладной дидактической дисциплиной, поэтому в основе обучения ему лежат принципы общей дидактики. Однако специфика иностранного языка как учебного предмета позволяет выделить и обосновать частные принципы, которыми следует руководствоваться при обучении языку в целом. С другой стороны, обучение языку студентов неязыкового профиля существенно отличается от его преподавания любой другой аудитории. Это позволяет выделить и обосновать в данной статье особые принципы подготовки к профессиональной межкультурной коммуникации студентов неязыко- 


\section{Филология: научные исследования 1(17) 2015}

вого профиля как специфического педагогического процесса. Данные принципы вытекают из общеметодических принципов и взаимосвязаны с ними.

Подготовка к профессиональной межкультурной коммуникации в неязыковом вузе, как и любой образовательный процесс, опирается в первую очередь на общедидактические принципы. Актуальность таких принципов, как сознательности, активности, доступности, научности, учёта возрастных особенностей и т.д. не вызывает сомнений в процессе передачи любых знаний, в том числе и лингвистических. Поэтому в данной статье мы более подробно рассмотрим и обоснуем специфические принципы обучения иностранному языку в целом и студентов нелингвистического профиля в частности.

В практике подготовки к профессиональной межкультурной коммуникации в вузе специфика преподавания языка студентам именно неязыкового профиля часто не учитывается. Основная причина тому заключается в том, что преподаватели, работающие в нём, сами закончили языковые вузы и факультеты. В случае отсутствия научного осмысления особенностей лингвистической подготовки нелингвистов, преподаватель с большой долей вероятности будет склоняться к тому, чтобы учить их так, как изучал язык профессионально сам, особенно в случае отсутствия у него большого опыта работы с разной аудиторией.

Вопрос о принципах обучения иностранному языку стал актуальным вместе с развитием и становлением в начале прошлого века методики обучения иностранным языкам как частной дидактики.

Совершенно очевидно, что у каждой учебной дисциплины своя специфика, и научное обоснование тех или иных способов обучения ей подразумевает выведение наиболее общих законов, на основе которых можно было бы разрабатывать новые, более совершенные методы обучения, а также которыми можно было бы руководствоваться при определении его содержания.

Такими специалистами в этой области, как Н.Д. Гальскова, Г.А. Китайгородская и Е.Н. Соловова выделяются следующие частнодидактические принципы обучения иностранному языку, полностью раскрывающие специфику подготовки к профессиональной межкультурной коммуникации.

1) Принцип коммуникативной направленности обучения. Он представляется одним из основных на современном этапе. В его контексте понятие «обучение иностранному языку» должно быть тождественно понятию «обучение коммуни- кации на иностранном языке». Поскольку основной функцией любого языка является коммуникативная, смысл этого принципа можно свести к тому, что преподавание иностранного языка должно быть ориентировано на формирование у обучающихся черт билингвальной языковой личности, делающих их способными к равноправному и автономному участию в межкультурной коммуникации, в том числе и в профессиональной [15].

2) Принцип интеграции и дифференциации. Суть интеграции заключается в данном случае в том, что какому бы аспекту иностранного языка не обучались бы студенты, одновременно в большей или меньшей степени задействуются и будут формироваться все остальные виды речевой деятельности. Суть дифференциации при этом состоит в том, что для того чтобы формировать каждый отдельный вид речевой деятельности и аспект языка, нужно использовать особые упражнения и задания, которые строятся с учётом специфических механизмов, находящихся в основе формирования каждого отдельного речевого и языкового навыка.

3) Принцип учёта родного языка. На сегодняшний день нет единого представления о том, в каком объёме должен использоваться родной язык на занятиях по иностранному. Однако очевидно, что на занятиях он может быть как положительным, так и отрицательным фактором. В основе данного принципа лежат два противоположных явления: перенос и интерференция. Если в процессе обучения иностранному языку можно провести некоторые параллели с родным, установить общие закономерности, то будет меньше сложностей. Это положительное влияние называется переносом. Причём речь здесь идет не только о языковой стороне вопроса, но и о тех навыках изучения языка, которые возможно перенести с родного на иностранный. Но часто у иноязычных лингвистических явлений нет аналогов в родном языке, либо они используются по-другому. В этом случае имеет место отрицательное явление, называемое языковой интерференцией [16].

4) Принцип ролевой организации учебного материала и процесса обучения. Общеизвестно, что общение становится творческим, личностно-мотивированным процессом, когда обучающиеся не имитируют коммуникацию, оперируя некоторыми навыками, а владеют её мотивом, совершая мотивированные речевые поступки. Практика обучения коммуникации на иностранном языке показывает, что низкий уровень коммуникативной мотивации 
является одной из серьёзных причин низкой активности и неудач студентов. Ролевые формы организации обучения позволяют наполнить речь и поведение обучающихся социально значимым содержанием.

5) Принцип организации коллективного взаимодействия. Данным принципом связываются цели обучения и развития личности, а также характеризуются средства и условия единого педагогического процесса. Его можно определить как такой способ организации учебного процесса, при котором:

a) происходит активное и интенсивное общение студентов друг с другом, обмен учебной информацией;

б) между студентами складывается благоприятное взаимодействие и формируется коллективная эмпатия, которая выступает в качестве условия повышения эффективности учебного процесса;

в) условие успеха каждого - успех других членов группы.

В условиях активного межличностного общения возникает ситуация познавательного развития учащихся, когда есть возможность формирования необходимых познавательных и исполнительских коммуникативных действий и операций обобщенно в широком контексте социальной функции осваиваемой коммуникативной деятельности. В постоянном и активном взаимодействии друг с другом студенты не просто обмениваются лингвистическими знаниями, подсказывают нужное слово или грамматическую форму, разъясняют правило своему товарищу, но и обучаются общению [17].

Итак, мы видим, что иностранный язык как учебная дисциплина обладает спецификой, определяющие принципы обучения ей. При этом сам по себе язык не является наукой, но он и наука о нём лингвистика фактически связаны со всеми науками и сферами знания, поскольку без языка существование никакой другой науки невозможно.

Подготовка к профессиональной межкультурной коммуникации студентов неязыкового профиля - ещё более специфический педагогический процесс. Учитывая его особенности, помимо общедидактических и частнодидактических принципов, возможно выделить некоторые особые принципы, которыми следует руководствоваться в процессе организации обучения иностранным языкам студентов-нелингвистов.

1) Принцип обучения современному языку. Этот принцип должен являться ведущим при фор- мировании содержания обучения ему студентов неязыкового профиля. В педагогической практике вопрос отбора языкового материала для лингвистической подготовки в непрофильном вузе стоит весьма остро. На это существует ряд причин. 1) Небольшое количество часов, отведённых на изучение иностранного языка. 2) Разный базовый уровень студентов. 3) Интересы студентов неязыкового профиля, не связанные напрямую с лингвистикой и филологией. Это является вполне объективной ситуацией, и было бы неправильно упрекать в отсутствии тяги к лингвистике людей, которые заведомо выбрали для себя другое профессиональное направление.

Учитывая в особенности последний пункт, при отборе материала для этих студентов в любом случае нужно осознавать, что в будущем они будут пользоваться иностранным языком только таким, каким он предстаёт на современном этапе своего развития. Сейчас даже язык зарубежных классиков начала XX в. является существенно устаревшим, не говоря уже о языке более ранних периодов.

Тем не менее, несмотря на это обучение профессиональных лингвистов и филологов в наши дни по-прежнему ведётся в большой степени на материале именно такого языка. Это можно объяснить следующим образом:

1) Для профессионала в области иностранного языка существенным фактором формирования профессионального и общекультурного мировоззрения является чтение классической литературы;

2) Человек с языковым образованием должен иметь диахроническое представление о языке, которым он владеет. Это подразумевает знания того, как язык менялся за время своего существования, а также понимание особенностей современного языка в противопоставлении его языку более ранних периодов.

Для выпускников неязыкового профиля эти знания и представления будут бесполезными с профессиональной точки зрения и вряд ли вызовут какой-либо личностный интерес, поскольку все наиболее значимые произведения зарубежной классики переведены на русский язык.

Таким образом, включение в программы лингвистической подготовки студентов неязыкового профиля материалов, основанных на классике неправильно с методической точки зрения. Эти программы следует формировать на основе таких аутентичных материалов, как: а) газетные статьи и интернет-публикации, б) материалы блогов, 


\section{Филология: научные исследования 1(17) 2015}

в) песни современных иностранных исполнителей, г) фрагменты из произведений современных зарубежных авторов [18; 19; 20].

Однако это не означает, что студентов в непрофильном вузе не следует знакомить с классиками зарубежной литературы. Для этого нужно находить материалы, рассказывающие об их жизни и творчестве, но написанные на современном языке. В наше время доступность Интернета значительно облегчает эту задачу.

С другой стороны, возможности Интернета при создании учебных пособий для неязыковых вузов у нас пока ещё используются не полностью, и процент актуальных аутентичных материалов в них по-прежнему невелик. В этой связи ключевой для реализации принципа обучения современного языку является деятельность преподавателя. Использование учебника как основного компонента образовательной программы не должно мешать органично вплетать в занятия современный языковой материал, взятый из газет, Интернета и других источников. Особенно это касается лексического материала, поскольку лексика, как известно, наиболее нестабильный и изменяющийся со временем аспект языка.

2) Принцип профессиональной ориентированности обучения. Данный принцип основывается на том, что знания иностранного больше всего пригодятся выпускникам в профессиональной деятельности. Безусловно, владение иностранными языками важно в современном мире и с точки зрения общекультурного развития личности. Знание иностранных языков, конечно, даёт сегодня человеку массу преимуществ и вне профессиональной деятельности. Однако основной задачей вуза всё же остаётся подготовка специалистов, конкурентоспособных на рынке труда. Если выпускник испытывает трудности с трудоустройством, даже являясь всесторонне развитой личностью, это не может идти в плюс вузу, подготовившему его. Сегодня даже неглубокий анализ вакансий с заработной платой выше среднего позволяет сделать вывод, что владение иностранным уже нельзя рассматривать как преимущество. Это скорее является нормальным требованием к кандидату, в то время как незнание языка представляет существенный недостаток.

Профессионально ориентированное обучение иностранному языку не может сводиться только к обучению профессиональной терминологии, как это часто бывает на практике. На это существует ряд причин:
1) Современные реалии таковы, что многие люди работают по смежному профилю или вообще не по профилю, поэтому нельзя предугадать, какая именно профессиональная терминология понадобится выпускнику после вуза;

2) Терминология постоянно меняется, особенно в областях, где ежегодно появляются новые явления и соответственно - термины;

3) Терминология - это в любом случае только лексические единицы. Обучение языку не может сводиться только к обучению лексики. Просто знать слова недостаточно, нужно знать особенности их употребления и уметь грамотно употреблять их в речи.

В содержание профессионально-ориентированного обучения языку должны входить коммуникативные ситуации, возникающие в ходе социального и профессионального взаимодействия представителей современных профессий в целом. Это так называемый деловой иностранный язык, если говорить об английском, то это business English. Изучающие английский в нашей стране словосочетание «business English» часто понимают как язык, использующийся в сфере коммерции, однако, в английском слово «business» обозначает более широкое понятие, чем соответствующее русское слово. В английском им обозначается не только коммерция и торговля, но и профессиональная деятельность квалифицированного специалиста в целом.

Тем не менее, большинство отечественных пособий по деловому английскому построены вокруг сугубо коммерческой деятельности, в этом они уступают аутентичным зарубежным учебником, в которых затрагиваются профессиональные проблемы значительно более широкого круга людей.

В учебных планах некоторых направлений подготовки присутствует дисциплина «Иностранный язык (деловой)» или «Профессиональный иностранный язык». Тем не мене, ситуации из профессиональной деятельности должны находить место на протяжении всего периода изучения иностранного языка в вузе.

На практике данный принцип хорошо реализуется за счёт включения в образовательный процесс интерактивных форм занятий языком. К ним в первую очередь относятся деловые и ролевые игры, в которых обыгрываются профессиональные или околопрофессиональные ситуации.

3) Принцип результативности и прикладного значения приобретаемых знаний, умений и навыков. Этот принцип близок к рассмотренному преды- 
дущему, однако, он затрагивает не отбор содержания обучения языку, а особенности мотивации студентов неязыкового профиля в данном процессе.

Сколько бы ни говорилось в теории о важности непрофильных общегуманитарных дисциплин для становления будущего профессионала, на практике отношение студентов к непрофильным предметам в большинстве случаев сводится к формуле «сдал и забыл» или вообще «списал и всё». Одна из причин тому - недостаточно совершенная, часто формальная система оценивания студентов в вузе.

Этот стереотип уже настолько силён, что к непрофильным предметам формально иногда уже начинают относиться даже преподаватели. Между тем мотивация к изучению иностранного языка любого студента повысится, если он будет видеть результат своих усилий, и будет осознавать, что применить полученные знания возможно на практике. Причём очень важно, чтобы эта практика была за рамками учебной деятельности. Очень часто дидактический принцип практичности сводится лишь к тому, что студентам объясняется правило, а потом даются упражнения для применения правила на практики. Такая практика является чисто учебной и не может выступать источником мотивации в высшей школе. Необходимо, чтобы студент ощутил возможность применять язык в повседневной деятельности, чтобы это могло вылиться в последующее применение его в деятельности профессиональной. Это во- прос тесно связан с вопросом организации самостоятельной работы студентов во внеучебное время, который сегодня тоже является весьма актуальным для педагогики высшей школы [21; 22].

Проанализировав приведённые принципы, в качестве заключения возможно сделать вывод, что они взаимосвязаны и вытекают из принципов иноязычной подготовки в целом. Так, например, принцип обучения современному языку вытекает из принципа коммуникативной направленности обучения, поскольку именно на современном языке происходит реальное общение людей. Принцип профессионально-ориентированного обучения связан с принципом ролевой его организации, поскольку в подобных формах, студенты приобретают коммуникативные навыки и качества, которые пригодятся им в профессиональной деятельности без относительно языка, на котором они будут говорить. Принцип результативности и прикладной значимости связан с принципом учёта родного языка. Действительно, чем выше у студента мотивация к изучению языка, там больше ему самому захочется исключить родной язык там, где это возможно, то есть читать новости, журналы, газеты на иностранном языке вместо привычного русского, смотреть фильмы и т.д. При этом родной язык по-прежнему может и должен быть полезен на занятиях, если он помогает сравнивать русские и иноязычные лингвистические явления.

\section{Список литературы:}

1. Аниол А.В. Межкультурная коммуникация и ее роль в процессе обучения бакалавров и магистров // Образовательные ресурсы и технологии. 2014. № 4(7). С. 54-61.

2. Рибокене Е.В. Институциональная среда постиндустриального информационного общества // Вестник Московского университета им. С.Ю. Витте. Серия 1: Экономика и управление. 2014. № 2(8). С. 137-139.

3. Флеров О.В. Повышение эффективности обучения студентов иностранному языку на основе коммуникативной методики: Автореф. дис. ... канд. пед. наук. М., 2013.

4. Гусев Д.А. Либерализм, православие и национальная идея в условиях переходного периода и кризиса современного российского общества // Философская мысль. 2015. № 2. С. 25-62.

5. Пробин П.С. Отечественная образовательная реформа в контексте современной конъюнктуры рынка труда: контуры интерпретаций // Социодинамика. 2015. № 3. С. 1-26.

6. Рибокене Е.В. Экономическое поведение потребителей в условиях транзитивной экономики России: Дис. ... канд. экон. наук. Саратов, 2001.

7. $\quad$ Гатиатуллина Э.Р. Горек ли корень учения? Или к вопросу о личности педагога в образовательном процессе // Современное образование. 2015. № 2. С. 20-44.

8. Гусев Д.А. К вопросу о риторической культуре преподавателя высшей школы // Современное образование. 2015. № 2. С. 141-176.

9. Руденко Ю.С. О проблемах реализации компетентностного подхода в высшей школе // Образовательные ресурсы и технологии. 2012. № 1(1). С. 4-8.

10. Комочкина Е.А. Обучение иностранным языкам в неязыковом вузе: история и современность. 2014 . № 7. С. $30-37$.

11. Флеров О.В. Корпоративное обучение английскому языку как способ повышения уровня коммуникативной компетенции сотрудников международных компаний // Современное образование. 2015. № 2. C. 116-140.

12. Флеров О.В. Особенности преподавания английского языка студентам с высоким уровнем языковой подготовки // Современное образование. 2015. № 1. С. 100-123. 


\section{Филология: научные исследования 1(17) • 2015}

13. Флеров О.В. Особенности преподавания второго иностранного языка в нелингвистическом вузе // Современное образование. 2015. № 1. С. 1-25.

14. Гусев Д.А. Docendo discimus - Уча, мы учимся сами. М., 2013.

15. Гальскова Н.Д. Теория обучения иностранным языкам. Лингводидактика и методика. М.: Академия, 2008.336 с.

16. Соловова Е.Н. Методика обучения иностранным языкам. Базовый курс. М.: АСТ, 2008. 238 с.

17. Китайгородская Г.А. Интенсивное обучение иностранному языку. М.: Высшая школа, 2009. 280 с.

18. Ершова О.В. Концепты «мотивация» и «интерес» как средства повышения эффективности контроля учебной деятельности студентов вуза // Высшее образование сегодня. 2013. № 8. С. 79-81.

19. Флеров О.В. Блог как средство обучения английскому языку // Педагогика и просвещение. 2014. № 4. С. 66-73.

20. Флеров О.В. Современная зарубежная популярная музыка как средство обучения английскому языку студентов нелингвистического профиля // Человек и образование. 2014. № 4(41). С. 141-143.

21. Гусев Д.А. Экзамен - всегда «праздник»? // Высшее образование в России. 2003. № 2. С. 84-86.

22. Ершова О.В. Историко-педагогический анализ эволюции контроля учебной деятельности // Высшее образование сегодня. 2013. № 9. С. 51-53.

23. Малышева А.Н. Теоретические трактовки полезности в образовании // Известия Южного федерального университета. Технические науки. 2011. № 1(114). С. 216-220.

24. Полякова Е.И. Технологии активного обучения в практике формирования у студентов интереса к освоению опыта межкультурного взаимодействия // Вестник российского университета дружбы народов. Серия: Психология и педагогика. 2008. № 4. С. 79-83.

25. Флеров О.В. Исправление ошибок в устной речи студентов в ходе коммуникативного обучения иностранным языкам // Высшее образование сегодня. 2012. № 7. С. 63-65.

26. Алешинская Е.В. Современные англоязычные музыкальные композиции как социолингвистическое явление и их использование для повышения интереса студентов к изучению английского языка // Litera. 2014. № 3. C. $148-165$. (DOI: 10.7256/2409-8698.2014.3.14619. URL: http://www.e-notabene.ru/fil/article_14619.html).

27. Завьялова Н.А. Универсалии современной коммуникации как отражение национального характера // Психология и психотехника. 2014. № 4. C. 377-386. (DOI: 10.7256/2070-8955.2014.4.11493).

28. Немцев И.А. Внедрение идей и принципов устойчивого развития в российское образование // Современное образование. 2014. № 4. C. 23-50. (DOI: 10.7256/2409-8736.2014.4.13524. URL: http://www.e-notabene.ru/pp/ article_13524.html).

\section{References (transliteration):}

1. Aniol A.V. Mezhkul'turnaya kommunikatsiya i ee rol' v protsesse obucheniya bakalavrov i magistrov // Obrazovatel'nye resursy i tekhnologii. 2014. № 4(7). S. 54-61.

2. Ribokene E.V. Institutsional'naya sreda postindustrial'nogo informatsionnogo obshchestva // Vestnik Moskovskogo universiteta im. S.Yu. Vitte. Seriya 1: Ekonomika i upravlenie. 2014. № 2(8). S. 137-139.

3. Flerov O.V. Povyshenie effektivnosti obucheniya studentov inostrannomu yazyku na osnove kommunikativnoi metodiki: Avtoref. dis. ... kand. ped. nauk. M., 2013.

4. Gusev D.A. Liberalizm, pravoslavie i natsional'naya ideya v usloviyakh perekhodnogo perioda i krizisa sovremennogo rossiiskogo obshchestva // Filosofskaya mysl'. 2015. № 2. S. 25-62.

5. Probin P.S. Otechestvennaya obrazovatel'naya reforma v kontekste sovremennoi kon"yunktury rynka truda: kontury interpretatsii // Sotsiodinamika. 2015. № 3. S. 1-26.

6. Ribokene E.V. Ekonomicheskoe povedenie potrebitelei v usloviyakh tranzitivnoi ekonomiki Rossii: Dis. ... kand. ekon. nauk. Saratov, 2001.

7. Gatiatullina E.R. Gorek li koren' ucheniya? Ili k voprosu o lichnosti pedagoga v obrazovatel'nom protsesse // Sovremennoe obrazovanie. 2015. № 2. S. 20-44.

8. Gusev D.A. K voprosu o ritoricheskoi kul'ture prepodavatelya vysshei shkoly // Sovremennoe obrazovanie. 2015 . № 2. S. 141-176.

9. Rudenko Yu.S. O problemakh realizatsii kompetentnostnogo podkhoda v vysshei shkole // Obrazovatel'nye resursy i tekhnologii. 2012. № 1(1). S. 4-8.

10. Komochkina E.A. Obuchenie inostrannym yazykam v neyazykovom vuze: istoriya i sovremennost'. 2014. № 7. S. 30-37.

11. Flerov O.V. Korporativnoe obuchenie angliiskomu yazyku kak sposob povysheniya urovnya kommunikativnoi kompetentsii sotrudnikov mezhdunarodnykh kompanii // Sovremennoe obrazovanie. 2015. № 2. S. 116-140.

12. Flerov O.V. Osobennosti prepodavaniya angliiskogo yazyka studentam s vysokim urovnem yazykovoi podgotovki // Sovremennoe obrazovanie. 2015. № 1. S. 100-123.

13. Flerov O.V. Osobennosti prepodavaniya vtorogo inostrannogo yazyka v nelingvisticheskom vuze // Sovremennoe obrazovanie. 2015. № 1. S. 1-25.

14. Gusev D.A. Docendo discimus - Ucha, my uchimsya sami. M., 2013.

15. Gal'skova N.D. Teoriya obucheniya inostrannym yazykam. Lingvodidaktika i metodika. M.: Akademiya, 2008. 336 s.

16. Solovova E.N. Metodika obucheniya inostrannym yazykam. Bazovyi kurs. M.: AST, 2008. 238 s.

17. Kitaigorodskaya G.A. Intensivnoe obuchenie inostrannomu yazyku. M.: Vysshaya shkola, 2009. $280 \mathrm{s.}$ 
18. Ershova O.V. Kontsepty «motivatsiya» $\mathrm{i}$ «interes» kak sredstva povysheniya effektivnosti kontrolya uchebnoi deyatel'nosti studentov vuza // Vysshee obrazovanie segodnya. 2013. № 8. S. 79-81.

19. Flerov O.V. Blog kak sredstvo obucheniya angliiskomu yazyku // Pedagogika i prosveshchenie. 2014. № 4. S. 66-73.

20. Flerov O.V. Sovremennaya zarubezhnaya populyarnaya muzyka kak sredstvo obucheniya angliiskomu yazyku studentov nelingvisticheskogo profilya // Chelovek i obrazovanie. 2014. № 4(41). S. 141-143.

21. Gusev D.A. Ekzamen - vsegda «prazdnik»? // Vysshee obrazovanie v Rossii. 2003. № 2. S. 84-86.

22. Ershova O.V. Istoriko-pedagogicheskii analiz evolyutsii kontrolya uchebnoi deyatel'nosti // Vysshee obrazovanie segodnya. 2013. № 9. S. 51-53.

23. Malysheva A.N. Teoreticheskie traktovki poleznosti v obrazovanii // Izvestiya Yuzhnogo federal'nogo universiteta. Tekhnicheskie nauki. 2011. № 1(114). S. 216-220.

24. Polyakova E.I. Tekhnologii aktivnogo obucheniya $\mathrm{v}$ praktike formirovaniya $\mathrm{u}$ studentov interesa $\mathrm{k}$ osvoeniyu opyta mezhkul'turnogo vzaimodeistviya // Vestnik rossiiskogo universiteta druzhby narodov. Seriya: Psikhologiya i pedagogika. 2008. № 4. S. 79-83.

25. Flerov O.V. Ispravlenie oshibok v ustnoi rechi studentov v khode kommunikativnogo obucheniya inostrannym yazykam // Vysshee obrazovanie segodnya. 2012. № 7. S. 63-65.

26. Aleshinskaya E.V. Sovremennye angloyazychnye muzykal'nye kompozitsii kak sotsiolingvisticheskoe yavlenie i ikh ispol'zovanie dlya povysheniya interesa studentov k izucheniyu angliiskogo yazyka // Litera. 2014. № 3. S. 148-165. (DOI: 10.7256/2409-8698.2014.3.14619. URL: http://www.e-notabene.ru/fil/article_14619.html).

27. Zav'yalova N.A. Universalii sovremennoi kommunikatsii kak otrazhenie natsional'nogo kharaktera // Psikhologiya i psikhotekhnika. 2014. № 4. S. 377-386. (DOI: 10.7256/2070-8955.2014.4.11493).

28. Nemtsev I.A. Vnedrenie idei i printsipov ustoichivogo razvitiya v rossiiskoe obrazovanie // Sovremennoe obrazovanie. 2014. № 4. S. 23-50. (DOI: 10.7256/2409-8736.2014.4.13524. URL: http://www.e-notabene.ru/pp/article_13524.html). 